\title{
The effect of different gases on the ultrasonic response of coal
}

\author{
Mark J. Lwin ${ }^{1}$
}

\begin{abstract}
To gauge the potential of seismic methods for the estimation of gas content in coal, the ultrasonic response of a sample saturated in turn with $\mathrm{He}, \mathrm{N}_{2}, \mathrm{CH}_{4}$, and $\mathrm{CO}_{2}$ has been investigated. Specifically, traveltimes were used to determine P-wave velocity as a function of the difference between confining pressure and pore pressure. After crushing the sample to powder, adsorption isotherms for $\mathrm{CO}_{2}$ and $\mathrm{CH}_{4}$ were measured and then used to estimate the bulk densities, $\mathrm{P}$-wave moduli, and impedances during the traveltime measurements. The data suggest a significant difference in density, P-wave modulus, and impedance under $\mathrm{CO}_{2}$ relative to $\mathrm{CH}_{4}$ saturation. Though these findings are based on the assumption that adsorption capacity of the sample when confined was similar to that measured after crushing, they are also roughly supported by isostatic strain measurements taken during swelling. Two possible causes of this behavior are, first, the mechanical properties of the adsorbed phase may be more liquid than gaslike. Second, the swelling of coal under confining pressure should lead to the closure of soft pores, thus stiffening the frame.
\end{abstract}

\section{INTRODUCTION}

It has become desirable to understand the seismic/sonic response of coal as a function of fluid content, especially in the context of restructuring the world's economy for a low-emissions future. For example, in countries such as Australia where it is anticipated that regulatory regimes will require reporting of greenhouse emissions, there will be a need for better methods to account for gas-in-place in coal mines. Furthermore, it is expected that where carbon trading schemes or taxes are in place, the coal seam gas industry will use the preferential adsorption by coal of $\mathrm{CO}_{2}$ over $\mathrm{CH}_{4}$, in a process known as enhanced coal bed methane (ECBM), to both enhance production of $\mathrm{CH}_{4}$ and offset costs through credits obtained for $\mathrm{CO}_{2}$ storage. An ability to estimate concentration and composition of gas in a coal seam saturated with either $\mathrm{CO}_{2}$ or $\mathrm{CH}_{4}$ based on a seismic/sonic contrast would obviously be useful. This would not be possible if fluids in coal behaved as in a conventional sandstone reservoir where the rock is considered inert and the only contribution to a difference in seismic/sonic response, due to the presence of different gases, is through their similar gas-phase mechanical properties. However, as is discussed below, the behavior of coal in the presence of fluids is quite different.

Coal has a nanoporous structure and therefore a large internal surface area to which large amounts of fluid can become bound via van der Waals forces. This interaction is known as physical adsorption. Not only do large amounts of fluid become bound, but uptake also varies significantly between different species. For instance, a study (Saghafi et al., 2007) of the in situ adsorption capacity of coals from the Sydney Basin, Australia, showed a variation in maximum $\mathrm{CO}_{2}$ storage capacity of between 40 and $80 \mathrm{~m}^{3}$ per ton. This corresponds to a density change of up to approximately $10 \%$ relative to a dry density of $1300 \mathrm{~kg} / \mathrm{m}^{3}$. The same study noted the adsorption capacity of $\mathrm{CH}_{4}$ and $\mathrm{N}_{2}$ to be about $1 / 2$ and $1 / 6$, or in mass terms, roughly $1 / 6$ and $1 / 18$, respectively, of that for $\mathrm{CO}_{2}$. This large density contrast under $\mathrm{CO}_{2}$ saturation compared with other gases will have a commensurate effect on velocity and impedance. Of course, these figures represent the maximum uptake, and in general, in-seam concentrations will be lower.

Given the amount of gas that can be adsorbed, it is not surprising that, at least in the case of $\mathrm{CO}_{2}$, the results of a neutron scattering study by Melnichenko et al. (2009) suggest that the density of the adsorbed state can be considerably larger (up to that of the liquid phase) than the free gas. This implies that the modulus of the adsorbed phase may also be more liquid-like. If so, a contrast in total modulus similar to that distinguishing liquid from gas saturation can be expected to exist between strongly and weakly adsorbed species.

Physical adsorption on solid (like liquid) surfaces reduces surface energy, or equivalently surface-tension (which is defined as surface energy per unit area) (Bangham, 1937; Yates, 1954) leading to a

\footnotetext{
Manuscript received by the Editor 7 July 2010; revised manuscript received 3 February 2011; published online 14 November 2011.

${ }^{1}$ Curtin University, Department of Exploration Geophysics, Cooperative Research Centre for Greenhouse Gas Technologies (CO2CRC), Perth, Australia. E-mail: m.lwin@curtin.edu.au.
}

(C) 2011 Society of Exploration Geophysicists. All rights reserved. 
positive volumetric strain known as swelling. This is readily understood when it is realized that surface-tension is derived from an asymmetrical distribution of molecular forces at an interface and will therefore under vacuum (hydrostatic effects aside) have a compressive effect (Yates, 1954). The adsorption of fluids produces swelling by reducing this asymmetry. Because of its large internal surface-to-volume ratio, this effect can be significant in coal. For example, Pan and Connell (2007) cite cases of one-dimensional strain of the order of $1 \%$ for unconfined samples immersed in $\mathrm{CO}_{2}$ at several $\mathrm{MPa}$, with strain induced by $\mathrm{CH}_{4}$ about one-half of this. These authors modeled bulk swelling under the implicit assumption that it is driven by an internal negative hydrostatic stress, in which porosity was unaffected, much like that discussed by Yates (1954). Though a satisfactory description of bulk strain, it is an inadequate description for the purpose of accounting for the effect of swelling on seismic response. This is because it does not predict a reduction of porosity such as observed under room conditions for wet, as opposed to dry coal (water, like many gases produces a substantial swelling effect [Fry et al., 2009]). Liu and Rutqvist (2010) have recently explained the effect of swelling on permeability. They have defined an effective stress for pore strain by including an internal swelling pressure, which is added to the confining stress and is therefore compressive with respect to pore strain. The tendency to swell, which is known to cause a reduction in permeability through the compression of relatively soft fractures, should for the same reason increase the elastic modulus of (or stiffen) the rock frame. The sensitivity of rock moduli to effective stress, resulting from the presence of soft porosity is well known (see, for example, Mavko and Jizba (1991) or Avseth et al (2005)).

Finally, Larsen (2004) has conjectured that in addition to being adsorbed, $\mathrm{CO}_{2}$ is absorbed (dissolves in) by, and consequently acts as a plasticizer, of coal (the term sorption encompasses both adsorption and absorption). If one interprets this as meaning that the matrix then acts in a viscoelastic manner, a frequency-dependant change in the elastic properties of the solid frame can be expected, with a relative softening at low compared to high frequencies. The gases $\mathrm{CH}_{4}, \mathrm{~N}_{2}$, and $\mathrm{He}$ are not thought to plasticize coal.

Observations (McCrank and Lawton, 2009) of the 3D seismic response of a $\mathrm{CO}_{2}$ plume injected into a water-saturated seam are of interest, despite an absence of comparative information on other gases. These authors observed a slight decrease in impedance not accounted for by Gassmann's equation and have given two possible reasons for this (for a discussion of the effect of fluid properties on seismic contrast predicted by this equation, see Mavko et al, 2009 , p. 273). First, in contrast to the view stated above, it was suggested that there might be a decrease in modulus due to a reduction of surface-tension at the solid-fluid interface. This nonlinear effect is possible in view of the large absorption-induced strains observed at MPa pore pressures. However, it is not consistent with work in which a constant modulus was used to model unconfined adsorption-induced strain at elevated pore pressure (Pan and Connell, 2007). Second, citing Larsen (2004), it was suggested that $\mathrm{CO}_{2}$-induced plasticization may have caused a matrix softening. Though credible, this does not immediately follow from the plasticization of coal, as it is not known if a softening will be manifest at seismic frequencies.

To investigate the matter of the effect of different gases on the seismic/sonic response of coal, I have performed laboratory measurements of ultrasonic P-wave velocity on a bituminous sample as a function of both the difference in confining and pore pressure (i.e., "differential" pressure) as well as adsorbed gas species. At the same time, axial sample length was monitored with linearly variable displacement transducers (LVDTs). Adsorption curves for $\mathrm{CO}_{2}$ and $\mathrm{CH}_{4}$ were then obtained for the same sample after it had been crushed to a powder. I have used this latter data to estimate density during the velocity measurements and hence allow an estimate of ultrasonic P-wave modulus and impedance. The results indicate a significant increase in density, $\mathrm{P}$-wave modulus and impedance for $\mathrm{CO}_{2}$ - over $\mathrm{CH}_{4}$-saturated coal and are discussed in the light of the behavior outlined above. In addition, a framework for calculation of the magnitude of that effect resulting from the compression of soft pores, as a function of the amount and species of adsorbed gas, is discussed.

It is acknowledged that sorption capacity of a powdered sample after crushing will not necessarily be similar to that of the same sample in bulk form and under confining stress. It is thought that confining stress may reduce adsorption capacity through a reduction in the aperture of nanometer-sized pores. On the other hand, it is thought possible that, for larger pores, confining stress may increase adsorption capacity through a cooperative interaction between adsorbate molecules on opposing pore walls (G. Birkett, personal communication, 2010). Little published data on absorption by intact confined coal exists, although Pone et al (2009) have measured a reduction of $\mathrm{CH}_{4}$ adsorption capacity by an intact sample at confining pressures of 6.9 and $13.8 \mathrm{MPa}$ (3 MPa pore pressure) of around $90 \%$ relative to a similar powdered sample. On the other hand, Jikich et al (2009) observed a relatively small reduction $(5 \%-10 \%)$ in uptake of $\mathrm{CO}_{2}$ at a confining pressures of up to $5.5 \mathrm{MPa}$ (pore pressure up to $4 \mathrm{MPa}$ ). The aforementioned aside, it will be seen that the ultrasonic response predicted herein by using the sorption data from the powdered sample corroborates with what would be expected based on the axial strain data obtained during time-of-flight measurements. It is argued that this justifies the use of sorption data from a powdered sample as an approximation, and supports the essential nature of the conclusions drawn.

\section{METHOD}

I performed this experiment on a single 77-mm-long, 38-mmdiameter plug that had been dried in an $\mathrm{N}_{2}$ atmosphere for several weeks after its extraction from of a block of bituminous coal. The plug axis was perpendicular to the bedding plane. The block was obtained from the Peak Downs mine in central Queensland. This sample was designated PD2-6. No attempt was made to remove atmospheric gases from the sample by applying a vacuum before the experiments.

First, I measured P-wave velocity as a function of the differential pressure (confining pressure minus pore pressure) by ultrasonic time-of-flight measurements on the sample confined in a Hoek cell, while under saturation with each gas in turn (see Figure 1 for schematic). Prior to gas injection, I carried out three bedding-in cycles, at atmospheric pore pressure (no-gas), in which uniform confining pressure was increased from 5 to $40 \mathrm{MPa}$ and back. Both the axial pressure, which was applied through a hydraulic ram and the lateral pressure, which was applied across a membrane in which the sample is enclosed, were controlled manually by independent hand pumps. Tests were conducted beforehand to ensure that all pressure gauge readings were consistent to within a fraction of $1 \%$. 
Helium was then injected to $5.1 \mathrm{MPa}$, while maintaining a positive differential pressure. Full saturation was taken to have been established by constant outputs from 3 LVDTs set up to monitor axial displacement throughout the experiment. I then loaded the sample from 5 to $35 \mathrm{MPa}$ differential pressure, while recording traveltimes. After this, the confining pressure was reduced to its initial value and the gas was vented. This procedure was repeated for $\mathrm{N}_{2}, \mathrm{CH}_{4}$, and $\mathrm{CO}_{2}$ also injected at $5.1 \mathrm{MPa}$ in turn. After venting and prior to injection of the next gas, I established repeatability of loading at low differential pressure by time-of-flight measurements. Variations in these measurements, at $5 \mathrm{MPa}$, span a period of approximately $0.25 \mu \mathrm{s}$. The sampling interval was $0.1 \mu \mathrm{s}$. I had established during the bedding-in cycles that variation in timeof-flight from cycle to cycle, at atmospheric pore pressure, quickly became unresolvable as differential pressure increased. Due to differing degrees of swelling and the consequent effect on permeability, the time required to reach saturation varied from 4 hours for helium, to 1-2 days for $\mathrm{CO}_{2}$. Times allowed for venting were slightly longer. The period for each loading-release cycle was the same, with incremental differential pressure increases and corresponding traveltime measurements made at 10-minute intervals. The temperature was $275 \pm 1 \mathrm{~K}$.

To determine ultrasonic P-wave velocities, I first estimated a relative time-of-flight by crosscorrelation with a baseline obtained for the sample at the same differential pressure but with no-gas. To this, I then added the absolute time-of-flight of the baseline. Only the first peak of each waveform (see Figure 2) was used in the crosscorrelation, as it is the only part of the directly arriving P-wave resolved from the many scattered and reflected wavelets forming a significant tail (not shown in the figure) and containing most of the transmitted power. The first peak is approximately equal in width to the extra time of travel for an indirect arrival reflected off the sample sides. This method provides a measurement approximately equal to the phase velocity of the received central frequency (roughly $150 \mathrm{kHz}$ as determined by fast Fourier transform [FFT]).

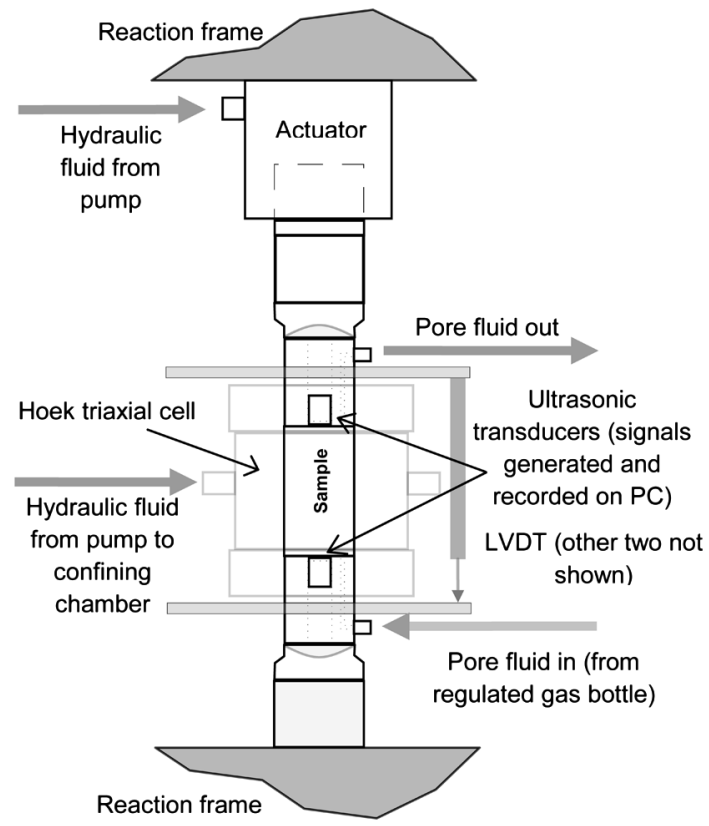

Figure 1. Schematic of apparatus used in traveltime measurements.
Corrections to distance of travel due to loading caps and changes in sample length, as logged by the LVDTs have also been made.

The same sample was then crushed for the purpose of carrying out "proximate and ultimate" analysis, petrographic analysis and adsorption isotherms under $\mathrm{CO}_{2}$ and $\mathrm{CH}_{4}$ saturation. The former two, the results of which are shown in Tables 1,2, and 3, were carried out in commercial laboratories according to Australian standards, while the latter was performed at the University of Queensland, Australia (see acknowledgments).

Adsorption isotherms were obtained by the volumetric method. In this method, gas at a known pressure is released from a reference volume into the sample chamber, also of known volume. The dependant variable is the final pressure of the system. Knowing

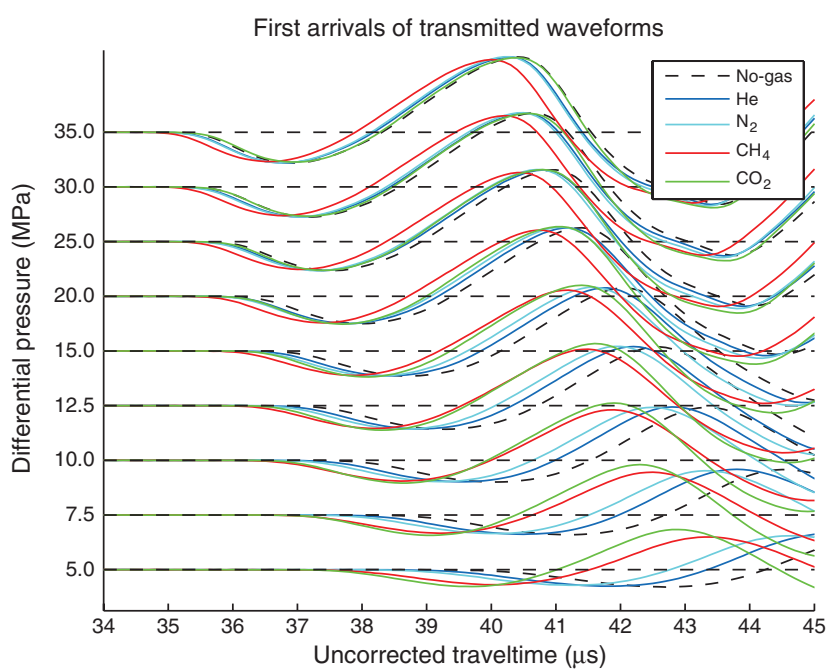

Figure 2. First arrivals of the transmitted waveforms, at differential pressures 5-35 $\mathrm{MPa}$, when saturated in turn with each gas. Also shown is the waveform recorded prior to the first gas injection (no-gas) and used as a baseline for the timing of the others.

Table 1. Proximate and ultimate or elemental analysis (d.a.f., i.e., dry ash free) of sample PD2-6.

Sample number

PD2-6

Proximate analysis

Moisture \%

Ash \%

14.0

Volatile matter $\%$

19.0

Fixed carbon $\%$

66.0

Total sulphur $\%$

0.58

Carbonate carbon \%

Ultimate analysis (d.a.f.)

Carbon \%

88.72

Hydrogen \%

Nitrogen \%

1.98

Sulfur \%

Oxygen \% 
the pressure that would have been attained in the absence of the adsorbing sample, one can then calculate the "amount excess." This quantity is the amount of gas in the system per unit mass of adsorbent above or below that which would be present at the same temperature and pressure without the adsorbent. To calculate the absolute amount of gas adsorbed, the volume of gas displaced by the adsorbent is added to the amount excess. Calculation of the displaced gas requires knowledge of the porosity that is often obtained by using helium. Instead, I have estimated the porosity iteratively, using a starting value of $5 \%$, as that which is consistent with the volume required to accommodate the adsorbed $\mathrm{CH}_{4}$ at a liquid phase density of $350 \mathrm{~kg} / \mathrm{m}^{3}$ (bulk liquid $\mathrm{CH}_{4}$ has a density approximately equal to $350 \mathrm{~kg} / \mathrm{m}^{3}$ just below $190 \mathrm{~K}$ ). Although higher than many literature values of porosity, it is stressed that the ultrasonic response as determined by using the procedure is not particularly sensitive to porosity over the range of $5-14 \%$. An estimate of the density during the time-of-flight measurements is provided by the mass sum of the amount excess, the displaced gas, and the solid, divided by the frame volume. The mass of displaced gas can be closely approximated by multiplying gas density data (Lemmon et al., 2009) by the solid volume. A small correction to frame volume (1\% and $2 \%$ for $\mathrm{CH}_{4}$ and $\mathrm{CO}_{2}$, respectively) was made to account for swelling. Density under helium saturation can be approximated by assuming that helium is not adsorbed.

\section{RESULTS}

Figure 2 shows the waveforms of the first arrivals after transmission through the sample during the loading cycles, and Figure 3 shows the $\mathrm{P}$-wave velocities calculated from this data. There is a systematic increase in $\mathrm{P}$-wave velocity as a function of differential pressure for $\mathrm{He}, \mathrm{N}_{2}$, and $\mathrm{CH}_{4}$ saturation in turn. The $\mathrm{CO}_{2}$ curve crosses the $\mathrm{CH}_{4}$ curve and is substantially flatter.

Figure 4(a) shows the adsorption curves for $\mathrm{CH}_{4}$ and $\mathrm{CO}_{2}$, and Figure 4(b) shows the total sample density due to this level of adsorption, as a function of pore pressure. Thus, at a pore pressure of $5.1 \mathrm{MPa}$, the bulk density during the time-of-flight measurements could be as much as $3.4 \%$ and $12 \%\left(49 \mathrm{~m}^{3}\right.$ and $66 \mathrm{~m}^{3}$ per ton of

Table 2. Petrographic analysis of sample PD2-6.

\begin{tabular}{|c|c|c|c|c|c|c|c|c|c|}
\hline Maceral & $\begin{array}{c}\text { Vol. \% } \\
\text { (aa) }\end{array}$ & $\begin{array}{l}\text { Vol. \% } \\
\text { (mmf) }\end{array}$ & $\begin{array}{l}\text { Maceral } \\
\text { Subgroup }\end{array}$ & $\begin{array}{l}\text { Vol. \% } \\
\text { (aa) }\end{array}$ & $\begin{array}{l}\text { Vol. \% } \\
\text { (mmf) }\end{array}$ & Maceral & No. & $\begin{array}{l}\text { Vol. \% } \\
\text { (aa) }\end{array}$ & $\begin{array}{l}\text { Vol. \% } \\
\text { (mmf) }\end{array}$ \\
\hline & & & & & & Textinite & 0 & 0.0 & 0.0 \\
\hline & & & Telovitrinite & 35.1 & 37.2 & Texto-ulminite & 0 & 0.0 & 0.0 \\
\hline \multirow[t]{7}{*}{ Vitrinite } & 59.1 & 62.7 & & & & Attrinite & 0 & 0.0 & 0.0 \\
\hline & & & Detrovitrinite & 24.0 & 25.5 & Densinite & 0 & 0.0 & 0.0 \\
\hline & & & & & & Desmocollinite & 124 & 24.0 & 25.5 \\
\hline & & & & & & Corpogelinite & 0 & 0.0 & 0.0 \\
\hline & & & & & & Cutinite & 0 & 0.0 & 0.0 \\
\hline & & & & & & Resinite & 0 & 0.0 & 0.0 \\
\hline & & & & & & Liptodetrinite & 0 & 0.0 & 0.0 \\
\hline \multirow[t]{7}{*}{ Liptinite } & 0.0 & 0.0 & & 0.0 & 0.0 & Alginite & 0 & 0.0 & 0.0 \\
\hline & & & & & & Suberinite & 0 & 0.0 & 0.0 \\
\hline & & & & & & Fluorinite & 0 & 0.0 & 0.0 \\
\hline & & & & & & Exsudatinite & 0 & 0.0 & 0.0 \\
\hline & & & & & & Bituminite & 0 & 0.0 & 0.0 \\
\hline & & & & & & Fusinite & 18 & 3.5 & 3.7 \\
\hline & & & Telo-inertinite & 27.3 & 29.0 & Semifusinite & 123 & 23.8 & 25.3 \\
\hline
\end{tabular}


coal) for $\mathrm{CH}_{4}$ and $\mathrm{CO}_{2}$, respectively, above the no-gas value. Porosities of $0.12-0.16$ and 0.22 for $\mathrm{CH}_{4}$ and $\mathrm{CO}_{2}$, respectively, are required to accommodate this amount of adsorbed gas, even assuming liquid-like adsorbed phase densities (approximately 300$400 \mathrm{~kg} / \mathrm{m}^{3}$ for bulk liquid $\mathrm{CH}_{4}$ below $190 \mathrm{~K}$ and $800 \mathrm{~kg} / \mathrm{m}^{3}$ for liquid $\mathrm{CO}_{2}$ at $295 \mathrm{~K}$ and 5.1 MPa (Lemmon et al., 2009). For the purposes of this discussion, a nominal porosity of 0.14 is used, and it is assumed that $\mathrm{CO}_{2}$ is both absorbed and adsorbed. Though this estimate is high in comparison with literature values, which vary from 0.03-0.1 (Melnichenko et al., 2009; Saghafi et al., 2007), it is consistent with the adsorption data.

Figure 5 shows the LVDT data that were recorded during both swelling and the loading cycles of each experiment for $\mathrm{He}, \mathrm{CH}_{4}$, and then $\mathrm{CO}_{2}$ saturation. It can be seen that the effect of pore expansion due to the presence of $\mathrm{He}$ is minor. On the other hand, the swelling strains produced by both $\mathrm{CH}_{4}$ and $\mathrm{CO}_{2}$ saturation are much larger. In the former case, the axial swelling strain is similar in magnitude to that produced by the $30 \mathrm{MPa}$ change in confining pressure during the loading cycle. In the latter case, it is roughly twice that produced by a $30 \mathrm{MPa}$ confining pressure. Finally, the compression phase data of the loading cycles have been used to produce the isostatic stress displacement curves shown in Figure 6.

Table 3. Vitrinite reflectance of sample PD2-6 mean maximum reflectance measured in oil.

\begin{tabular}{lccrc} 
& $R_{\mathrm{o} \max }$ & Range & $n$ & Standard deviation \\
\hline Telovitrinite & 1.38 & $1.32-1.48$ & 73 & 0.048 \\
Detrovitrinite & 1.36 & $1.33-1.43$ & 27 & 0.036 \\
Total vitrinite & 1.38 & $1.32-1.48$ & 100 & 0.047 \\
\hline
\end{tabular}

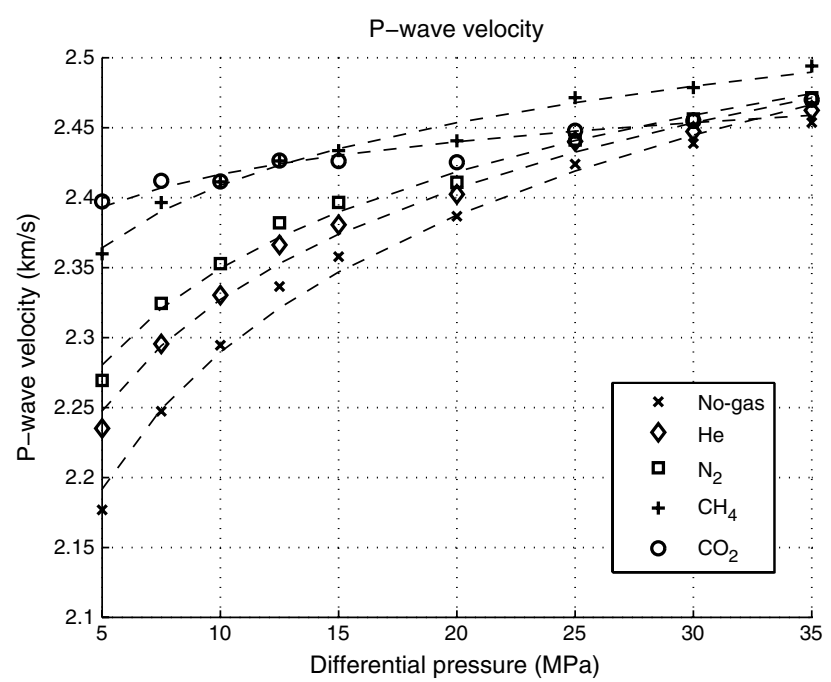

Figure 3. Ultrasonic P-wave velocities as a differential pressure. A sampling interval of $0.1 \mu \mathrm{s}$ and the variation in the timing baseline of $0.25 \mu \mathrm{s}$ (see text) contribute approximately $10 \mathrm{~ms}^{-1}$ to error in absolute velocity for the gas-saturated samples at $5 \mathrm{MPa}$ differential pressure. This diminishes at higher differential pressure due to the reduction in the baseline uncertainty. a)

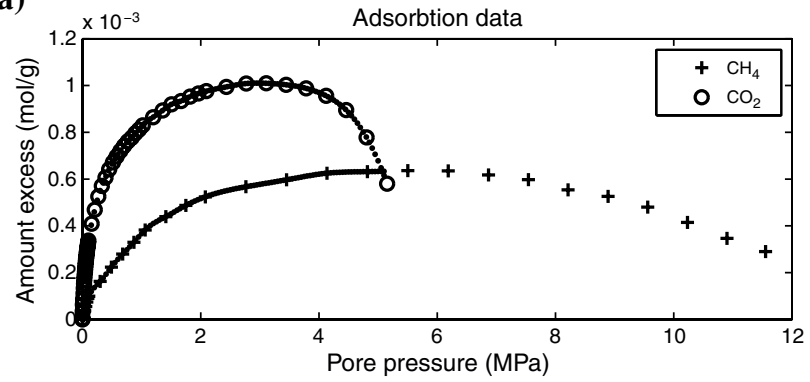

b)

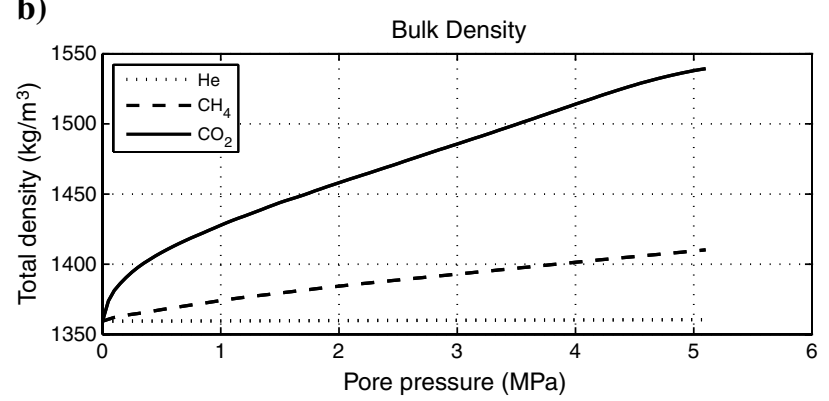

Figure 4. (a) Adsorption isotherms for $\mathrm{CH}_{4}$ and $\mathrm{CO}_{2}, T=295 \mathrm{~K}$. (b) Total density of sample, calculated as described in text.

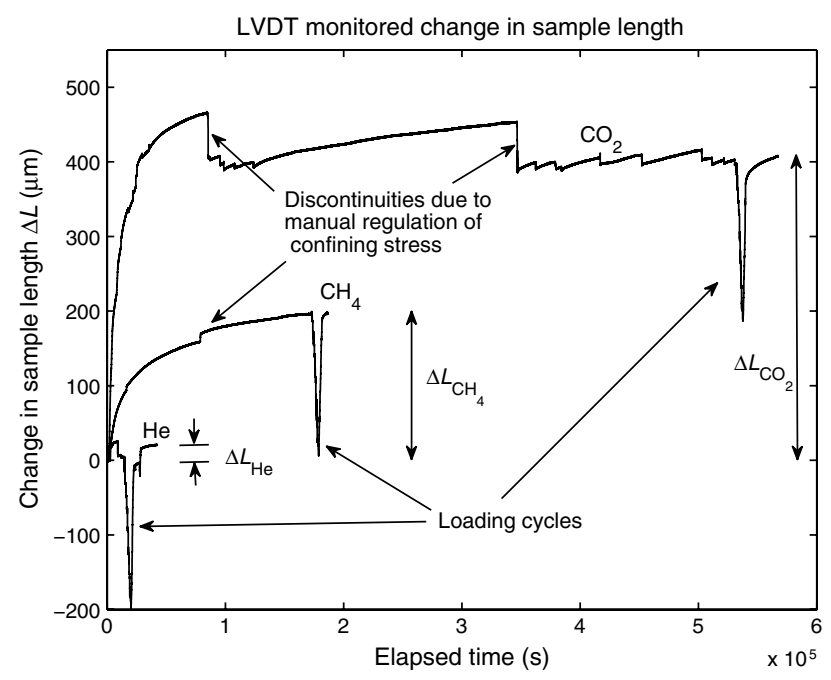

Figure 5. Averages of the sample axial length measurements, obtained from the three LVDTs, when saturated in turn with $\mathrm{He}, \mathrm{CH}_{4}$, and $\mathrm{CO}_{2}$. The period covered begins with gas injection at low differential pressure and continues through the period of swelling to the loading/unloading cycle during which the time-of-flight measurements were made. A complication is the variation in sample length due the manual regulation of pressure. In general, an expanding sample will cause a buildup of pressure in unregulated hydraulic lines. The manual release of this pressure produces an increase in the axial length. Such behavior was observed during $\mathrm{CH}_{4}$ flooding. In contrast, swelling during $\mathrm{CO}_{2}$ saturation produced larger pressure changes in the radial than the axial pressure lines. In this case, manual regulation of pressure resulted in a decrease in axial length. This may be related anisotropic swelling under $\mathrm{CO}_{2}$ saturation. 
As can been seen, there is a progressive increase in both the relative isostatic bulk modulus and the linearity of the curves, under $\mathrm{He}, \mathrm{N}_{2}$, and then $\mathrm{CH}_{4}$ saturation. On the other hand, in the case of $\mathrm{CO}_{2}$, there has been a decrease relative to $\mathrm{CH}_{4}$.

The velocity data of Figure 3 and the total densities calculated as described above have been used to estimate $\mathrm{P}$-wave modulus and $\mathrm{P}$-wave impedance under saturation with $\mathrm{He}, \mathrm{CH}_{4}$, and $\mathrm{CO}_{2}$. The resulting data as a function of differential pressure are shown in Figure 7(a) and (b). This figure shows a systematic and significant increase in both modulus and impedance (above $10 \%$ at low differential pressures) for the $\mathrm{CO}_{2}$ over the $\mathrm{CH}_{4}$-saturated case.

\section{DISCUSSION}

It was postulated in the introduction that an increase in modulus may be due to a denser and/or stiffer adsorbed phase, or a reduction in soft porosity due to swelling. Although an assessment of the former effect might be made (in the low-frequency limit), using liquid properties and Gassmanns equation, the information required to carry this out is not presently at hand (e.g., solid phase moduli, low-frequency data). The presence of the latter effect is, however, suggested by the quasistatic axial-stress displacement curves of Figure 6, which show an increasing quasistatic modulus, and an increase in linearity commensurate with the removal of soft pores, for $\mathrm{He}, \mathrm{N}_{2}$, and $\mathrm{CH}_{4}$ in turn. On the other hand, the $\mathrm{CO}_{2}$ curve shows a decrease relative to $\mathrm{CH}_{4}$. This may be due to plasticization.
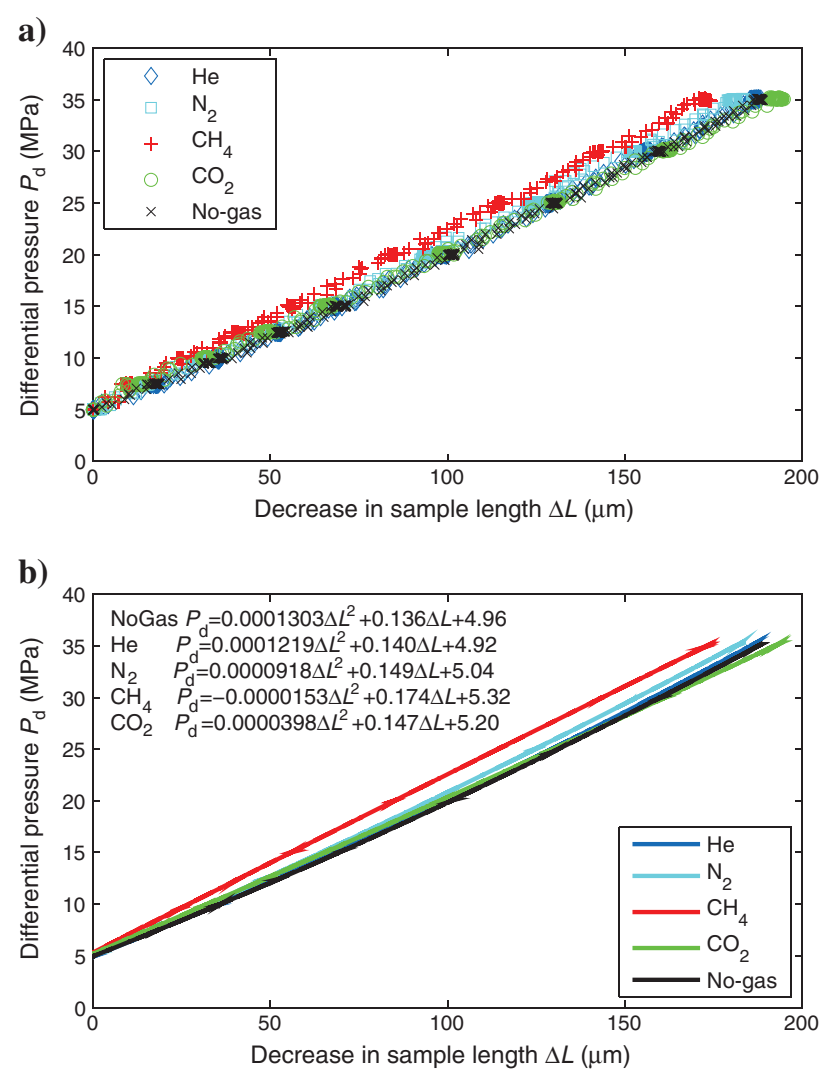

Figure 6. (a) Quasistatic axial compression data, under saturation by each of the gases $\mathrm{He}, \mathrm{N}_{2}, \mathrm{CH}_{4}$, and $\mathrm{CO}_{2}$, as determined by the average change in sample length as monitored by the three LVDTs. (b) Second-degree polynomial curves and explicit equations derived from least squares fitting to the data of (a).
The presence of plasticization by $\mathrm{CO}_{2}$ is, however, not evident in the ultrasonic waveforms. In the context of wave propagation, a viscoelastic effect should be apparent as an increase in dispersion (spreading) in the $\mathrm{CO}_{2}$ waveform relative to the others. An inspection of the first arrivals (at $5 \mathrm{MPa}$ differential pressure) after being superimposed (Figure 8) via a time shift determined by crosscorrelation, reveals that there is less dispersion during $\mathrm{CO}_{2}$ saturation, at this stress, than for the other gases. However, because the effect of swelling-induced pore closure will also affect dispersion but in the opposite sense to plasticization, the issue of whether the effects of the latter will be apparent at seismic or sonic frequencies is unresolved. It should be noted that waveforms recorded at higher differential pressure (not shown) indicate that the variation in dispersion in Figure 8 diminishes as differential pressure increases, so that at $35 \mathrm{MPa}$, the superimposed first arrivals are indistinguishable.

Notwithstanding the contribution of the adsorbed fluid to the modulus, it is obvious that in the light of the large strains observed during swelling, a significant effect on ultrasonic/seismic response is predicted by a modification to effective stress, such as defined by Liu and Rutqvist (2010). These authors have defined an effective stress with respect to pore strain and although both the elastic properties of coal and coal swelling are known to be anisotropic (Fry et al., 2009), under the approximation of isotropy, this definition can be expressed as

a)

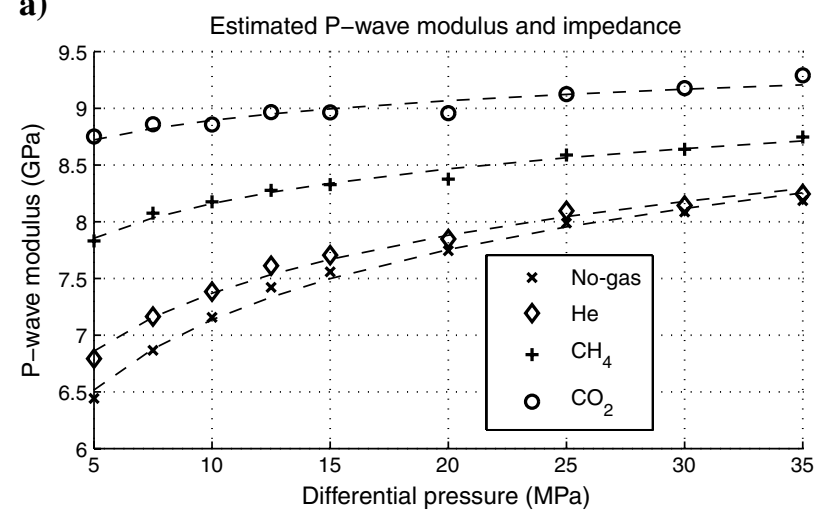

b)

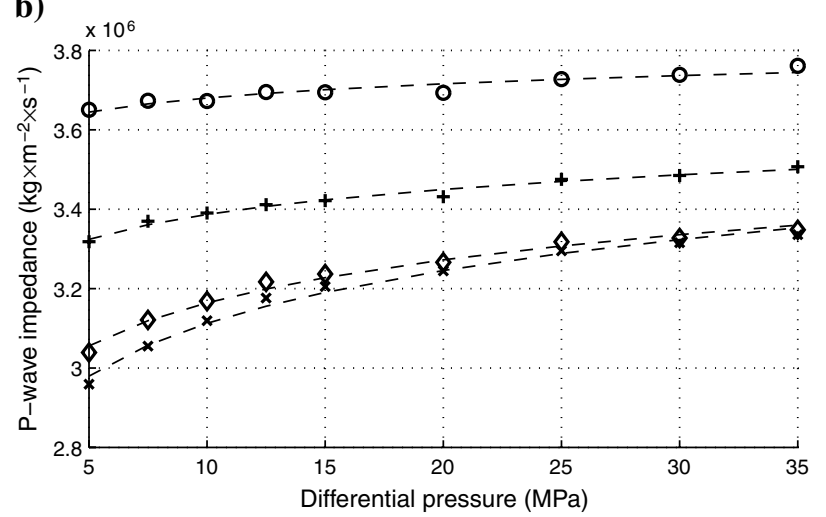

Figure 7. (a) Estimates of ultrasonic P-wave modulus and (b) P-wave impedance. Error in modulus and impedance are undetermined as they rely on an inferred density. 


$$
P_{e}=P_{c}+P_{\Phi}-\alpha P
$$

where $P_{c}$ is confining pressure, $P$ is the pore pressure, $0<\alpha \leq 1$ is measure of the effectiveness of pore pressure at relieving compressive pore strain, and $P_{\phi}$ is an effective pressure that drives swelling.

The characteristic behavior of the dependence of modulus upon effective pressure is a monotonic increase at a diminishing rate, approaching a horizontal line in the limit of pressure large enough to compress all pores. A shift equal to the swelling pressure $P_{\Phi}$ will produce curves that are higher (without exceeding the limit) and flatter for larger $P_{\Phi}$. These features are roughly displayed by the curves of Figure 7(a).

The effective swelling pressure $P_{\Phi}$ has been estimated based on the LVDT data in Figure 5. The results are shown in Table 4. It is noted that in the definition of effective stress for bulk strain, $P_{\Phi}$ will have the opposite sign of that used in equation 1 , which defines effective stress for pore strain (i.e., for bulk strain, $P_{e}=P_{c}-$ $\left.P_{\Phi}-\alpha P\right)$. The estimates of $P_{\Phi}$ based on the LVDT data and shown in Table 4 were made by multiplying the change in sample length due to swelling by an estimate of the modulus for drained compression (specifically, the secant slope obtained from the no-gas compression data shown in Figure 6). The changes in sample length due to $\mathrm{CH}_{4}$ and $\mathrm{CO}_{2}$ swelling were obtained by subtracting the change in sample length due to pore pressure only $\Delta L_{\mathrm{He}}$, from $\Delta L_{\mathrm{CH} 4}$ and $\Delta L_{\mathrm{CO} 2}$, the changes in length during $\mathrm{CH}_{4}$ and $\mathrm{CO}_{2}$ flooding, respectively.

For the moment, ignoring the possibility that the adsorbed fluid makes a significant contribution to the modulus, the swelling pressures $P_{\Phi}$ under $\mathrm{CH}_{4}$ and $\mathrm{CO}_{2}$ saturation have also been estimated from the shifts, relative to the He curve, in the modulus versus differential pressure curve of Figure 7(a). The shift, $P_{\Phi}$ for the $\mathrm{CO}_{2}$ curve was estimated by adding the shift in the $\mathrm{CO}_{2}$ curve relative to $\mathrm{CH}_{4}$, to the shift in the $\mathrm{CH}_{4}$ curve relative to the He curve. The results are also shown in Table 4. By their nature, these are imprecise quantities.

The following concerns a framework for calculating the size of the swelling pressure as a function of the amount and species of gas adsorbed. Pan and Connell (2007) used a micromechanical model due to Scherer (1986) to relate adsorption-induced strain in unconfined coal to the change in surface energy per unit mass $\Delta \Phi$ of adsorbent. For the purpose of calculating the swelling pressure, which by definition is a term they used to account for hydrostatic compression, can be ignored and their expression for strain $\Delta l / l$ reduces to

$$
\frac{\Delta \ell}{\ell}=-\frac{\Delta \gamma A \rho_{s}}{E_{s}} f\left(x, \nu_{s}\right)=-\frac{\Delta \Phi \rho_{s}}{E_{s}} f\left(x, \nu_{s}\right) .
$$

where $\Delta \gamma$ is the change in surface tension, $A$ is the specific surface area, and $\rho_{s}$ and $E_{s}$ are the solid phase density and Young's modulus. $f\left(x, \nu_{s}\right)$ is a dimensionless function of the solid phase Poisson's ratio $\nu_{s}$ and a parameter $x$ that is determined by the porosity $\phi$. The magnitude of the swelling pressure can be stated, using expressions for elastic constants of the model developed by Scherer (1977, 1985), as follows (see Appendix A):

$$
P_{\Phi}=3 K \frac{\Delta l}{l}=\Delta \Phi \rho_{s} g\left(\phi, \nu_{s}\right)
$$

where $K$ is the total bulk modulus and $g\left(\phi, \nu_{s}\right)$ is a function similar to $f\left(x, \nu_{s}\right)$, having magnitude of order unity except at porosities less than around $5 \%$.

For the purpose of calculating $\Delta \Phi$, Pan and Connell (2007) demonstrate that at modest pressures (such as the 5.1 MPa used herein), volume changes in the solid phase can be ignored so that the Gibbs adsorption isotherm gives a satisfactorily estimate. Thus, for unconfined adsorbents, at constant temperature and for modest pressures, $\Delta \Phi$ can be expressed as

$$
\Delta \Phi=\int_{1}^{2} n d \mu=\int_{1}^{2} n V d P,
$$

where, $n$ is the total number of moles adsorbed, $\mu$ is chemical potential, $V$ is specific volume of the gas, and $P$ is pore pressure. Assuming this approximation is also satisfactory for confined samples, the adsorption data of Figure 4 was used to obtain numerical solutions for $\Delta \Phi$ at a pore pressure of 5.1 MPa. Table 4 shows subsequently determined values for $P_{\Phi}$ calculated with equation 3 using $\phi=0.14$ and $\nu_{s}=0.38$ to give $g\left(\phi, \nu_{s}\right)=1.2$.

Referring to Table 4, the swelling pressures estimated from the strain data are seen to be roughly equal to the upper bound of the

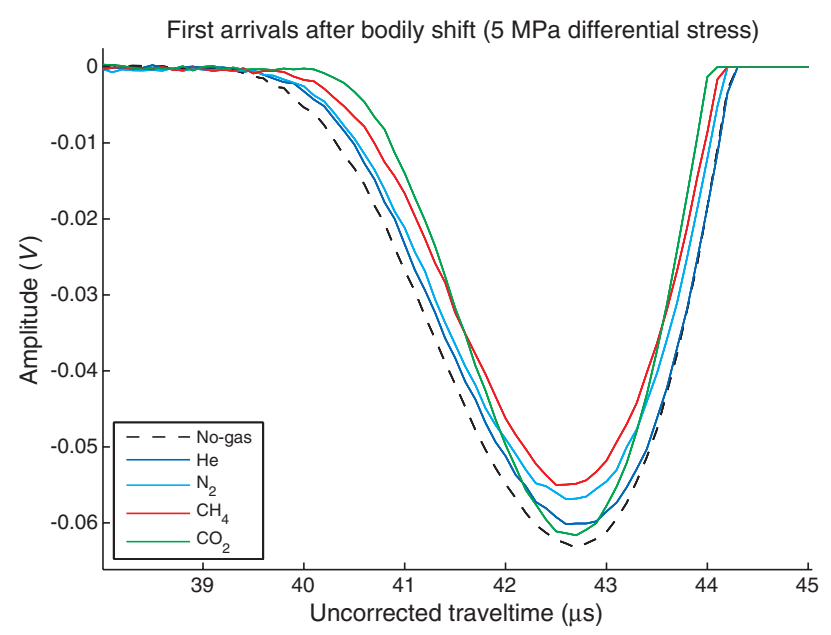

Figure 8. First peaks of the waveforms ( $5 \mathrm{MPa}$ differential pressure) after a bodily shift by a time determined by crosscoloration with the no-gas reference waveform. Note that amplitudes have not been normalized.

Table 4. The swelling pressure $P_{\Phi}$ as estimated first from LVDT data ${ }^{a}$; second, from the observed shift in the P-wave modulus curves ${ }^{\mathrm{b}}$; and third, as calculated from the change in surface energy $\Delta \Phi$.

Based on Observed shift in P-wave

LVDT data modulus curves Calculated

\begin{tabular}{lcccc}
$\mathrm{Gas}$ & $(\mathrm{MPa})$ & $(\mathrm{MPa})$ & $\Delta \Phi(\mathrm{J} / \mathrm{kg})$ & $(\mathrm{MPa})$ \\
\hline $\mathrm{CH}_{4}$ & 27 & $15-25$ & 6500 & 12.3 \\
$\mathrm{CO}_{2}$ & 59 & $45-55$ & 10300 & 19.5 \\
\hline
\end{tabular}

${ }^{\mathrm{a}} \mathrm{See}$ Figure 5.

${ }^{\mathrm{b}}$ See Figure 7(a).

${ }^{\mathrm{c}}$ See equation (3) 
estimated shifts in the modulus curves. Given that the latter are inferred results, as discussed, this degree of corroboration is probably all that could be expected at this stage of investigation. On the other hand, the calculated values are just below the lower bound for $\mathrm{CH}_{4}$ and significantly below for $\mathrm{CO}_{2}$. These calculations have, however, been included more for the purpose of discussion than with an expectation that they would provide accurate results at present. More work, both experimental and theoretical, is required before enough confidence can be placed in the data for qualitative purposes. Obviously, it would be ideal to carry out adsorption measurements simultaneously with time-of-flight measurements. Also, it is unlikely that the effect of $\mathrm{CO}_{2}$ sorption can be explained so simply. First, this is because of the issue of plasticization; and second, because it is felt the large amount of $\mathrm{CO}_{2}$ sorption that has occurred should contribute significantly to the modulus.

Although the confidence required to make quantitative predictions is still lacking, these results do suggest that in some circumstances, a significant contrast in seismic response will exist between coal containing $\mathrm{CH}_{4}$ and that containing $\mathrm{CO}_{2}$. In the context of EBCM, seismic impedance can be a more useful attribute than velocity as coal seams are often quite thin. The contrast in ultrasonic P-wave impedance shown in Figure 7(b) is 9\%-10\% of the value for the $\mathrm{CH}_{4}$ curve. Such contrasts are resolvable by surface seismic for seams of the order of $10 \mathrm{~m}$ (McCrank and Lawton, 2009). Also, the presence of cleats will increase sensitivity to effective-pressure. In the context of mining, gas levels are often of the order of a few cubic meters per ton or less. Lower concentrations of gas will naturally result in a reduced effect, perhaps limiting application to borehole techniques; although this will be mitigated somewhat by the nonlinearity in sensitivity, with greater sensitivity being expected at lower concentrations.

\section{CONCLUSIONS}

These experimental findings infer a significant contrast in both ultrasonic P-wave impedance and modulus of coal as a function of the adsorption of different gas species, in particular $\mathrm{CH}_{4}$ and $\mathrm{CO}_{2}$. Although this impedance contrast is in part due to a large relative change in density, the cause of the modulus contrast is not entirely certain, although it is thought to be due to at least two effects. The first is the presence of a large amount of adsorbed gas, particularly in the case of $\mathrm{CO}_{2}$, which can exist in a more dense and likely less compressible state than the free gas. Second, an effective internal pressure due to adsorption is thought to lead to the closure of compliant pores, stiffening the rock frame. It is proposed that within the approximation of isotropy, this effect be modeled as a shift in effective-pressure. Finally, although the plasticization of the sample by $\mathrm{CO}_{2}$ is suggested by quasistatic modulus data, this effect is expected to be frequency dependant and no evidence of plasticization was noted at the ultrasonic frequencies used in this work.

\section{ACKNOWLEDGMENTS}

This work was funded by the CO2CRC. Thanks to Doug Dunn, John Centofanti, and their colleagues at BHP Billiton Mitsubishi Alliance for provision of coal samples. Thanks also to Paul Massarotto and Greg Birkett of the University of Queensland for the adsorption measurements, proximate and ultimate analysis, and discussions relating to adsorption by coal.

\section{APPENDIX A}

\section{THE SWELLING PRESSURE AS PREDICTED BY SCHERER'S MODEL}

Scherer (1986) proposed the following model to describe the swelling behavior of porous glass. Pan and Connell (2007) justified the use of this model to calculate the uniaxial swelling of coal, partly because of Larsen's (2004) description of coal as having a cross-linked glassy structure. The model is composed of unit cells constructed from three orthogonally intersecting cylinders with base diameter $2 a$ and length $\ell$. Scherer (1986) derived the following expression relating one-dimensional strain $d \ell / \ell$ (i.e., strain along the length of a component cylinder) to the change in surface tension $\Delta \gamma$, times the internal surface area per unit mass of adsorbent $A$ (or alternatively the change in surface energy per unit mass $\Delta \Phi)$,

$$
\begin{aligned}
\frac{d \ell}{\ell} & =-\frac{\Delta \gamma A \rho_{s}}{E_{s}} f\left(x, \nu_{s}\right)=-\frac{\Delta \Phi \rho_{s}}{E_{s}} f\left(x, \nu_{s}\right), \\
f\left(x, \nu_{s}\right) & =\frac{\left[2\left(1-\nu_{s}\right)-\left(1+\nu_{s}\right) c x\right]\left[3-5 \nu_{s}-4\left(1-2 \nu_{s}\right) c x\right]}{\left(3-5 \nu_{s}\right)(2-3 c x)},
\end{aligned}
$$

where $x=a / \ell$ and $c=8 \sqrt{2} /(3 \pi)$. The solid phase volume of the cell is $V_{s}=3 \pi a^{2} \ell-3 \pi c a^{3}$ (Scherer, 1977). As the total cell volume is $V=\ell^{3}$, the porosity is given by

$$
\phi=1-3 \pi x^{2}+3 \pi c x^{3}
$$

Thus, $f^{\prime}\left(\phi, \nu_{s}\right)=f\left(x, \nu_{s}\right)$ can be determined from a knowledge of $\phi$ and $\nu_{s}$. Note that the porosity $\phi$ is that of the matrix, that is, it does not include cleats or cracks.

Scherer (1985) also provides relations between bulk and solidphase values of Young's modulus and Poisson's ratio for the cell, which as $\rho / \rho_{s}=(1-\phi)$, may be written in porosity terms as follows,

$$
\begin{gathered}
E=\frac{E_{s} \rho}{3 \rho_{s}-2 \rho}=\frac{E_{s}(1-\phi)}{3-2(1-\phi)}, \\
\nu=\nu_{s}\left(\frac{\rho}{3 \rho_{s}-2 \rho}\right)^{\frac{1}{2}}=\nu_{s}\left[\frac{(1-\phi)}{3-2(1-\phi)}\right]^{\frac{1}{2}} .
\end{gathered}
$$

One can now calculate the pressure that would be required to act across each face of the cubic cell to produce the volumetric strain $3 \Delta \ell / \ell$. That is,

$$
\begin{aligned}
& P_{\Phi}=-3 K \frac{d \ell}{\ell}=\frac{-3 E}{2(1-2 \nu)} \frac{d \ell}{l}=h\left(\phi, \nu_{s}\right) f^{\prime}\left(\phi, \nu_{s}\right) \Delta \Phi \rho_{s} \\
& =g\left(\phi, \nu_{s}\right) \Delta \Phi \rho_{s},
\end{aligned}
$$

where

$$
h\left(\phi, \nu_{s}\right)=\frac{1-\phi}{3-2(1-\phi)} \times \frac{1-\phi}{1-2 \nu_{s}\left[\frac{(1-\phi)}{3-2(1-\phi)}\right]} .
$$


The response is that of an effective medium constructed from a cubic array of cells. The fact that such a medium is cubic and not isotropic appears to have been ignored. It should also be pointed out that this model is constructed to describe media with midrange porosities, and that it fails at low porosity $(<0.05)$ below that in which the bases of the cylinders from adjacent cells start to overlap and the value of $g\left(\phi, \nu_{s}\right)$ approaches infinity. It was, however, used by Pan and Connell (2007) to model swelling for porosities as low as 0.049 .

\section{REFERENCES}

Avseth, P., T. Mukerji, and G. Mavko, 2005, Quantitative seismic interpretation: Cambridge University Press.

Bangham, D. H., 1937, Gibbs' adsorption equation and adsorption on solids: Transactions of the Faraday Society, 33, 805-811, doi: 10.1039/ tf9373300805.

Fry, R., S. Day, and R. Sakurovs, 2009, Moisture-induced swelling of coal International Journal of Coal Preparation and Utilization, 29, 298-316, doi: $10.1080 / 19392690903584575$.

Jikich, S. A., R. McLendon, K. Seshadri, G. Irdi, and D. H. Smith, 2009 , Carbon dioxide transport and sorption behavior in confined coal cores for carbon sequestration: SPE Reservoir Evaluation and Engineering, 12, $124-136$.

Larsen, J. W., 2004, The effects of dissolved $\mathrm{CO}_{2}$ on coal structure and properties: International Journal of Coal Geology, 57, 63-70, doi: 10.1016/ j.coal.2003.08.001

Lemmon, E. W., M. O. McLinden, and D. G. Friend, 2009, Thermophysical properties of fluid systems, http://webbook.nist.gov/chemistry/fluid/, accessed October 2009.
Liu, H., and J. Rutqvist, 2010, A new coal-permeability model: Internal swelling stress and fracture-matrix interaction: Transport in Porous Media, 82, 157-171, doi: 10.1007/s11242-009-9442-x.

Mavko, G., and D. Jizba, 1991, Estimating grain-scale fluid effects on velocity dispersion in rocks: Geophysics, 56, 1940-1949, doi: 10.1190/ 1.1443005 .

Mavko, G., T. Mukerji, and J. Dvorkin, 2009, The rock physics handbook: Tools for seismic analysis of porous media, 2nd ed.: Cambridge University Press.

McCrank, J., and D. C. Lawton, 2009, Seismic characterization of a $\mathrm{CO}_{2}$ flood in the Ardley coals, Alberta, Canada: The Leading Edge, 28, 820-825, doi: 10.1190/1.3167784.

Melnichenko, Y. B., A. P. Radlinski, M. Mastalerz, G. Cheng, and J. Rupp, 2009 , Characterization of the $\mathrm{CO}_{2}$ fluid adsorption in coal as a function of pressure using neutron scattering techniques (SANS and USANS): International Journal of Coal Geology, 77, no. 1-2, 69-79, doi: 10.1016/ j.coal.2008.09.017.

Pan, Z., and L. D. Connell, 2007, A theoretical model for gas adsorptioninduced coal swelling: International Journal of Coal Geology, 69, 243-252, doi: 10.1016/j.coal.2006.04.006.

Pone, J. D. N., P. M. Halleck, and J. P. Mathews, 2009, Sorption capacity and sorption kinetic measurements of $\mathrm{CO}_{2}$ and $\mathrm{CH}_{4}$ in confined and unconfined bituminous coal: Energy and Fuels, 23, 4688-4695.

Saghafi, A., M. Faiz, and D. Roberts, 2007, $\mathrm{CO}_{2}$ storage and gas diffusivity properties of coals from Sydney Basin, Australia: International Journal of Coal Geology, 70, 240-254, doi: 10.1016/j.coal.2006.03.006.

Scherer, G. W., 1977, Sintering of low-density glasses. I. Theory: Journal of the American Ceramic Society, 60, 236-239.

Scherer, G. W., 1985, Stress in leached phase-separated glass: Journal of the American Ceramic Society, 68, 419-426.

Scherer, G. W., 1986, Dilatation of porous glass: Journal of the American Ceramic Society, 69, 473-480.

Yates, D. J. C. 1954, Expansion of porous glass on adsorption of nonpolar gases: Proceedings of the Royal Society of London. Series A, Mathematical and Physical Science, 224, no. 1159, 526-544. 